\title{
Editorial: Psychotherapy for torture survivors - Suggested pathways for research
}

\author{
Pau Pérez-Sales, MD, PhD, Psych*, Editor in Chief
}

In its nearly 30 years of existence, the Torture Journal has published different reviews on individual or group psychotherapy for torture survivors ${ }^{1-6}$ and a number of studies on the effectiveness of a varied array of intervention models implemented by care centers $^{7-19}$ which are in addition to other seminal reviews on the subject. ${ }^{20-32}$

On the whole, the evidence to support one model of intervention over another is usually poor. It can be concluded that, overall, there are low to moderate outcome results for each model or technique and no clear conclusions when different models are compared. ${ }^{21,} 24,33,36$, 37 This led some authors ten years ago to say that the whole rehabilitation sector was a waste of money until it reached a respectable scientific status through the adoption of "evidence-based" therapeutic models. ${ }^{34}$ This in-turn generated a justifiable response of complaint from within the sector on rehabilitation of survivors of torture. ${ }^{35}$

\section{Two similar literature reviews with opposite recommendations: what is a reader to do?}

This unclear and somehow confusing situation is exemplified by the first 2016 issue of Torture Journal; two excellent

*) SiR[a] Centre, GAC Community Action Group and Hospital La Paz, Spain. reviews on best psychotherapeutic practices for torture survivors published one besides the other yielded not only different, but opposite recommendations. This undoubtedly deserves an editorial reflection and some proposals.

In the first review, based on their Cochrane meta-analysis, Patel, Williams and Kellezi ${ }^{1}$ conclude that there is no evidence to support one therapeutic technique over others in the rehabilitation of victims of torture. In particular, they were critical of the enthusiasm for cognitive-behavioural and exposure techniques, exemplified in Narrative Exposure Therapy (NET), for which, they say, there is more fervour than real evidence when rigorous criteria are applied and the size of the sample, statistical significance and follow-up data are carefully analysed: "Our conclusions for practice were that there was too little evidence, and it was too heterogeneous and of generally low quality to recommend any particular treatment, that none showed immediate benefit, and that longer term gains were hard to interpret" (p.13). In the second review, Weiss, Ugeto et al. ${ }^{6}$ based on a systematic review with less stringent criteria than those used by the Cochrane rules conclude exactly the opposite: that in reviewing DMS trauma-related disorders one by one, the only treatment that currently can be considered "evidence-based" are different forms of trauma-focused, cognitive-behavioural techniques (like NET) and using any 
1. Any torture rehabilitation center in any part of the world can do first-line research in psychotherapy with torture survivors with very few resources which would be potentially publishable in Torture Journal.

2. There is a long tradition of experimental research on common factors in psychotherapy that has not yet been integrated in the research of best practices for torture survivors. Contemporary research in psychotherapy has shifted from an interest in Evidence Supported Treatments (EST) based on Randomized Control trials of manualized procedures, to Empirically Supported Relationships (ESR) based on naturalistic or semi-naturalistic studies that compare true-life interventions. Both need to be combined.

3. There is no basis to assume that only CB techniques should be investigated and taught in training programs, and offered to individuals with mental health problems. CBT has only been proven to be superior to other treatments in its ability to alleviate "specific" symptoms. This is commendable but limited.
4. There is a need to shift from manualbased one-size-fits-all treatments to defining pathways of care tailoring programs to individual needs. This is also possible even for the smallest center with very basic resources and aligns with well-stablished Do-NoHarm principles.

5. Torture Journal wants to be a platform to promote both randomized clinical studies and evidence-based naturalistic studies, and to help develop models of psychotherapy that respond to the genuine needs of survivors from an understanding and respect for the social and political context in which the torture occurred, the characteristics of each survivor and his/her symbolic world of meanings, the style and the formation of each therapist (helper or healer) and the interaction between all these elements. 
technique instead of these with our current knowledge should be avoided, making an appeal to concentrate research efforts on these treatments: "We recommend that NGOs providing mental health services to survivors of torture and other systematic violence use CBT with exposure components to address PTSD, depression and anxiety. (...)" (p. 38). So, what is the reader to do? This gives food for thought, so it is worth taking a step backwards and reviewing the evidence.

The first and necessary reflection is to be aware of the pitfalls of reviews and meta-analysis. Wampold et al. ${ }^{36}$ have recently offered a compelling critique of three recent meta-analyses maintaining superior effects of cognitive behavioral therapy (CBT) over other psychotherapies, for psychopathology in general and for social phobia. The paper illustrates how easy it is to make basic errors in meta-analyses, and that the results of such meta-analyses can, like any other type of research, be interpreted in different ways; it could be termed a meta-analysis paradox. ${ }^{1}$

\section{Psychotherapy as a symbolic healing procedure: a common factors approach} More than twenty years ago, seminal exhaustive reviews by Wampold ${ }^{37}$ and Lambert ${ }^{38}$ concluded that when psychotherapies that are intended to be therapeutic (Bona Fide Psychotherapies) are compared, the true difference among all such treatments is zero. In other words, all psychotherapies in the long term yield similar results. This has been, since then, confirmed once and again in all reviews based on the comparison of psychotherapy interventions. ${ }^{39,40}$ Research in psychotherapy has shifted from an emphasis on techniques to an emphasis on an integrative, eclectical or common methods approach. The common factors explanation for therapeutic equivalence across various orientations observed in the psychotherapy outcome literature is both parsimonious and supported by scientific evidence. Rigorous observational studies clearly show that two senior therapists from opposite theoretical approaches, after years of attending patients, do in practice quite similar things. By contrast, this clearly diverges from what younger therapists of the same theoretical approach are doing when beginning in practice. ${ }^{40}$ In other words, experience slowly leads to a convergence of what therapists do.

Rosenzweig ${ }^{41}$ already said in 1936 that, "given a therapist who has an effective personality and who consistently adheres in his treatment to a system of concepts which he has mastered and which is in one significant way or another adapted to the problems of the sick personality, then it is of comparatively little consequence what particular method that therapist uses" (pp. 414-415).

Fiedler, in his series of observational studies, showed between 1950 and 1955 that systematic observation "clearly differentiates experts from nonexperts regardless of school. These factors are related to the therapist's ability to communicate with and understand the patient, and to his security and his emotional distance to the patient. No factors were found which clearly separate therapists of one school from those of another" (p. 38). ${ }^{40}$

Jerome Frank, initially an anthropologist, formulated in his book Persuasion and Healing the idea, rooted on Levi-Strauss' notions of symbolic therapies, that what a western, trained psychotherapist and a traditional healer from a non-western tradition do is basically the same. ${ }^{42}$ The difference is the kind of symbolism they use in their healing process. Frank evolved these ideas in successive editions of his well-known book into the Common Factors Theory. ${ }^{42}$ Different approaches and evidencebased practices in psychotherapy and counselling share common factors that account for much of the effectiveness of a psychological treatment. According to Frank, a healing process needs: 
(1) the expectation of help and improvement;

(2) a trusting therapeutic relationship;

(3) a rationale or conceptual scheme, meaningful to the patient, that explains the given symptoms and prescribes a given ritual or procedure for resolving them; and,

(4) the active participation of both patient and therapist in carrying out that ritual or procedure.

In other words, therapy is about creating a myth that explains the problem (myths can be narcissism, self-esteem, hot memories, family scapegoats, an Evil Eye, Latah, depression or post-traumatic stress disorder as explanatory models to be negotiated with the patient within the therapeutic contract) and carrying out a certain procedure (or psychotherapeutic ritual) in a structured manner that will ultimately lead to fulfilling expectancies of help, having access to new experiences and reasonings, and allow the patient to try different options and solutions to solve the myth previously agreed. It is in the experience of many of those who work with torture survivors that traditional healing therapies are not only a better solution, but can be the only possible solution for many of our non-western patients, who are likely to find the explanatory model and the proposal of shared work and ritual more significant. Said in a different way: a cognitive-behavioural therapist, a psychoanalyst and an EMDR therapist are indigenous western healers that use different myths to achieve quite similar results.

\section{Defining trans-theoretical common factors}

In 1990, an APA review on effective methods in psychotherapy found 89 trans-theoretical common factors from which 35 were finally selected and classified into five areas of research: patients' characteristics, therapist qualities, change processes, treatment structure, and therapeutic relationship. ${ }^{43}$

Lambert, probably the main author of reference in the field, found out after a series of reviews on experimental studies on psychotherapy outcomes and in successive editions of his well-known book ${ }^{39}$ that, when there is an improvement in a given patient, $40 \%$ is due to extra-therapeutic factors (life changes out of the therapeutic space), $30 \%$ to the climate of the interaction between therapist and patient that depends on common factors, $15 \%$ on the expectancies of a positive outcome from both therapist and especially the patient, and importantly only the remaining $15 \%$ on the specific technique used. The technique is relevant, but is it so relevant as to make it the sole focus of psychotherapy research as we seem to do today and as the two reviews mentioned above albeit implicitly suggest?

\section{And then came the Manuals}

At the end of the 1990s and the beginning of this century, psychotherapy research began to imitate pharmacological research and pretended to solve the dilemma of equivalent results among different psychotherapeutic traditions by manualizing therapies and comparing outcomes through randomized clinical trials (RCT) as if a psychotherapy was equivalent to an antibiotic or to chemotherapy. As amoxyciline is used as an evidencebased treatment for neumonia, the universal evidence-based therapy for each one of the five hundred or so DSM-V disorders must and will be found. Whilst there is a surely an important role for RCT's, this movement did not take into account the very signals from psychopharmacology itself: there is no specific psychiatric medication for any disorder. Antidepressants have a therapeutic impact on such varied problems as depression, social 
phobia, panic attack, negative psychotic symptoms and obsessive-compulsive disorder to cite only a few. Once and again, in the pharmacological domain, meta-analysis has shown that there is no single elective medication for a definite DSM-V disorder (such as PTSD) in spite of what the pharmaceutical industry tries to demonstrate. ${ }^{44,45}$

Imitating pharmacological research in the domain of psychotherapy or counselling by using strict manualized procedures as if they were pills implies four erroneous assumptions are made:

(a) that PTSD exists as a "disease" (like neumonia), when in fact psychiatric classifications and the definition of "disorders" change dramatically every ten years or so;

(b) that all patients labelled as having a certain "disease" (such as PTSD) are similar;

(c) that all therapists that apply a manual do it in the same way irrespective of their personal characteristics; and,

(d) that the interaction between a unique patient and a particular therapist will be equivalent.

None of these assumptions has ever been demonstrated to be true. These are the dangers of thinking manuals as cookbooks ${ }^{53}$ and not taking into account common factors in the psychotherapeutic work with survivors.

The position is, then, that research in psychotherapy established a long time ago that there is no intervention which is universally adequate for each DSM problem. There are, however, possible interventions for each time a therapist is confronted with a certain real life problem in a determined context within the realm of a therapeutic dialogue. Instead of putting the emphasis on the efficacy of a certain manual, the alternative option is examining the conditions and processes that make a certain therapeutic interaction successful. The technique chosen is, of course, relevant ( $15 \%$ of success, according to Lambert), ${ }^{39}$ but its contribution is minor when compared to the evolving context (psychosocial approach) and the common factors.

A summary of research in 2014 suggested a ranked order of importance. Although the debate clearly continues on what the list should be and the relative importance of each factor, the factors that most contributed to success in therapy were found to be: goal consensus/collaboration, empathy, strong therapeutic alliance, positive regard/affirmation, congruence/genuineness, and therapist personality. ${ }^{46}$ But there are many more suggested in literature. These areas clearly need to be the focus of thought and research as well as the treatment technique. Even more if programs are intended for non-western contexts when traditional healing has a long tradition of effective therapies. ${ }^{\text {i }}$

These issues are exactly what the reader can reflect on when reading the paper from Iselin Dibaj, Leif Edward Ottesen Kennair, Joar Øveraas Halvorsen and Håkon Inge Stenmark which is published in this issue and an additional contribution to the meta-analysis paradox. The authors designed a pilot study to find out whether a manualized combined treatment of NET plus physiotherapy is a successful treatment for comorbid PTSD and chronic pain in torture survivors. The results were that, in general, it cannot be concluded

${ }^{i}$ This opens the debate on whether traditional healing should be included in RCTs to show its effectiveness and put it under the lens of the "scientifically proven". There are strong epistemological and anthropological arguments against this position, although some non-randomised testing has been done as part of naturalistic or seminaturalistic studies ${ }^{64,66,67}$ and more research could probably be done if it does not colude with the healing process and the outcomes are consensual. 
that there is a significant positive effect. But if instead of considering it a therapeutic trial we read it as a repeated measures multiple single-case experimental study, we learn that two out of six patients clearly achieved a clinically significant reduction in symptoms of PTSD, one patient achieved clinically significant change in depressive symptoms and two experienced clinically significant reduction in pain intensity. The research question here is, thus, not whether NET plus physiotherapy is the best evidence-based approach for torture survivors with comorbid pain but how can we know which of the patients would benefit from it? If a wider scope is taken, this means considering the combination of patient and therapist characteristics and the interaction between them that will work and moving from the one-size-fits-all model to multimodal treatments and interventions that can be tailored to each profile of patients. The authors explain that the manual was not strictly followed with any of the patients because it simply was not possible. The detailed description of each case allows the reader to make some speculative hypothesis to be tested with a bigger sample and more systematic observations of the reasons for success or failure of each case. Such a study suggests that the challenge is being able to define tailored pathways of care and multimodal treatments.

When the Center for Victims of Torture developed a manual for group counselling of torture survivors (see book review in this issue pp 75-76), ${ }^{47}$ they adopted an integrative perspective drawing ideas from "cognitive behavioral theory, narrative exposure therapy, somatic psychology, interpersonal therapy, neuroscience, resilience- strength-based approaches, and CVT's own extensive experience" (pp. 1-2). Despite being called a 'manual', it is a wonderful starting point particularly because the focus should not be a question of whether it should be preferred over other alternative similar manuals based on Randomized Control Trials, but why this manual is successful in one country and has experienced difficulties in another. ${ }^{48}$ Why does it work in a geographical and political context and not in the same place two years later? Why is it appropriate for some patients and not others? Why does it work when used by a specific group of therapists and not with others? The manual is not an answer to a problem in itself. The manual is a therapeutic multimodal group of "myths" to be tested (either by parts or as an overall product) and thus the beginning of a compulsory and much-needed research process towards flexible interventions tailored to each interaction of problem-patient-therapist in a given context.

\section{The ethical question and the do-no- harm principle}

If the argument is taken one step further, it becomes even more convincing. If a certain therapeutic, manualized technique (such as NET or EMDR) is proven to be successful compared to another by a poor effect size at a three-month follow-up and not at six and twelve months (as has happened), the conclusion is not that NET or EMDR is preferable to other manuals as the only evidence-based approach. ${ }^{\text {ii }}$ The conclusion is that NET has worked for some patients,

\footnotetext{
ii The APA Task Force on evidence-based therapies for trauma suggest that brief trauma-focused cognitive therapies have a low to middle size evidence base as a preferable option for the treatment of trauma patients. The detractors of this conclusion have pointed out that the Task Force had a preference for short-term cognitive and behavioral techniques, largely because these studies are more prevalent in the literature as they can be easily manualized and submitted to case-control studies with comparatively little funds. Unfortunately, such qualities of research may be at variance with usual practice and may have skewed the definition of what "empirical validation" means.
} 
has done nothing for others, and has been damaging or iatrogenic for the rest (hopefully not many). A one-size-fits-all solution cannot work, even for the best available treatment. The key point must be how we can know what the preferable option is for each patient, taking into account the do-no-harm principle and what science tells us about psychotherapy; Common Factors are far more relevant that specific techniques, when there are around 200 models of manualized therapies recognised by the American Psychological Association (APA) ${ }^{49}$

Instead of focusing on certain narrative techniques as the only and best evidence-based current option, under a Common Factors perspective, the focus could be: if narrating really is a universal necessary condition for a therapeutic process in torture survivors, then which patients (therapist and interactions) could benefit from it?iii Beutler et al. ${ }^{50}$ define this line of reasoning and research as a process of systematic treatment selection and prescriptive therapy. This type of approach leads to the therapist and patient defining the problem together, building a culturally and contextually sensitive, meaningful explanation and finding out how to work together on it through a process built on a trusted relationship.

Manuals are only the very beginning of

\footnotetext{
iii A good and well-known example of this idea is what happened with Critical Incident Stress Debriefing (CISD), proposed as a manualized procedure by Mitchell in 1986. Different Cochrane reviews showed the dangers that the technique entailed and concluded that, overall, there was not a significant statistical effect and it should not be used in a compulsory way in the aftermath of trauma, ${ }^{47}$ in what later became an official WHO recommendation..$^{48}$ We know today that there are some conditions and contexts that might benefit from one-shot, brief trauma-focused interventions, while CISD proposing it as a universal one-size-fits all solution was an ethically unacceptable presumption.
}

this type of collaborative questioning. They can be useful as myths, but can be part of the problem when overtly relied upon.

\section{Psychotherapy as part of multimodal comprehensive interventions}

This conception positions psychotherapy as part of a wider picture, understanding that there are pre-trauma factors (i.e. childhood attachment experiences), factors related to trauma (type, duration, context and meaning of torture) and post-trauma factors (i.e. hostile or discriminating environments and traumatic experiences in host countries), the latter being the best predictors of long-term outcome. ${ }^{51-52}$ There are emerging mixed models, like the Common Elements Treatment Approach (CETA) for anxiety and mood disorders. Although it is a manualized, trauma-focused, evidence-based model, it includes some opportunities for flexibility and adaptation, allowing treatment without specifying a disorder classification and including guidance for delivering specific elements to patients with comorbidity. ${ }^{53}$ CETA was recently tested in a population of survivors of trauma and torture in two small RCTs, one in southern Iraq and one at the Thailand-Burma border with promising results ${ }^{\mathrm{iv}}$. Other flexible models are also emerging. ${ }^{53}$

These models do not in fact take into account what most of the literature calls common factors in psychotherapy (such as, building meaning, empathic bond, therapeu-

\footnotetext{
iv It is not a true cultural formulation based on ethnoconcepts of disease and healing, but a cultural adaptation. For instance, $100 \%$ of patients in both settings underwent Imaginal Exposure. Cultural adaptation refers to the way the material was presented to counsellors, not to the techniques in itself.
} 
tic alliance), but common techniques in psychotherapy (exposure, relaxation etc) ${ }^{55}$ which may be misleading. The idea behind them (tailoring interventions to different profiles of survivors and individualizing treatment), the methodology of development (having different blocks that can be altered in order and contents) and implementation procedures (RCT in low and middle income countries with lay workers) show a groundbreaking and revolutionary path. But let us be clear: as Dereubeis et al. summarize, ${ }^{65}$ the state of the art shows that, "If the question at hand is whether research is far enough along to support the view that only CBTs should be investigated, taught in training programs, and offered to individuals with mental health problems, then the answer is clearly "no." (...) CBTs and other disorder-specific therapies may be superior to other treatments in their ability to alleviate "specific" symptoms such as social anxiety, tics, or panic attacks” (p. 34). That's what we know.

Existential elements not captured by a clinical diagnosis must also be part of the rehabilitation process. The Adaptation and Development after Persecution and Trauma (ADAPT) model that includes five core adaptive systems subdivided into the basic human functions of "safety and security", "bonds, attachment and networks", "justice," "identity-role", and "existential meaning" and its operationalization is the best available example, to my knowledge, on how subtle existential elements can be integrated into a therapeutic model. ${ }^{56-59}$

\section{Integrating basic research into psychotherapy}

Torture entails special challenges. To design multimodal and flexible treatments we need to know more about the neurobiology of torture, ${ }^{60-62}$ etiopathogenic models of torture (that is, how torture affects the different subsystems of the human mind through analysis using the Scale of Torturing Environments for example), ${ }^{63}$ the interrelation between these torturing environments and the psychological structure of the survivor. This will help in going beyond PTSD-based models to more specific treatments that include, for instance, self-conscious emotions like shame or guilt, that clearly help to determine prognosis. While exposition might be helpful for some patients (even perhaps for most patients on average), let us, for instance, accept that a survivor with a strong internalizing psychological structure might benefit from supportive therapy and traditional healing more than crude exposition.

\section{Looking at the future}

In order to integrate a common factors approach into psychotherapy research with torture survivors, we need to look towards defining profiles of effect and therapeutic conditions, rather than only looking for universal therapies. As well as asking about the effectiveness of certain techniques, we need to be open to the common factors perspective: What patient profile and under what conditions do patients benefit from re-telling the experience of torture? How should this narration be carried out to be therapeutic? When can this narration have adverse or even iatrogenic effects? We need to do this to advance towards individualized therapies through pathways of care models. All studies are of potential importance from a survival and funding point of view.

However, efficiency is not only about how many hundreds of people we target, but if we are really being of help.

To advance in this direction we need to go beyond basic clinical studies based on general purpose clinical questionnaires frequently administered before and after a mixed unstructured treatment consisting often of 
manualized techniques. Such research is often only possible due to the resources of larger research centers and conclude that the intervention was partially effective without being able to go beyond that. Whilst this type of research is also surely needed, carefully designed semi-naturalistic studies done in local rehabilitation centers can also draw firm conclusions. For example, profiling what works for who under certain therapeutic conditions. Qualitative naturalistic studies and informed case studies can be used to formulate a hypothesis of specific interactions with respect to the problem/therapist/technique/ context. This goes hand-in-hand with the need to develop locally-based community indicators of resilience and healing that go beyond clinical measures and target the social fabric broken by political violence. The Torture Journal and other publications have already published some useful examples of this kind of semi-naturalistic research. ${ }^{64}$

These may in turn open the door to the design of an algorithm of treatment allowing randomised control trials to test the proposed algorithm (i.e. symbolic healing versus community support vs culturally-adapted cognitive behaviour therapy) or different combinations of it. Such studies would allow a new generation of a shared body of outcome studies to be carried out that integrate the Common Factors and Empirically Supported Treatment perspectives.

Perhaps this combination of naturalistic and experimental studies can help to solve the differing recommendations of the meta-analysis paradox set out above. ${ }^{1,6}$

\section{Acknowledgements}

Many thanks to the experts who provided comments and feedback on the content of this editorial. 
References

1. Patel N, Williams ACDC, Kellezi B. Reviewing outcomes of psychological interventions with torture survivors : Conceptual, methodological and ethical Issues. Torture J. 2016;26(1):2-16.

2. Bunn M, Goesel C, Kinet M, Ray F. Group treatment for survivors of torture and severe violence : A literature review. Torture. 2016;26(1):45-67.

3. Persson TJ, Rousseau C. School-based interventions for minors in war-exposed countries: a review of targeted and general programmes. Torture. 2009;19:88-101.

4. Jaranson JM, Quiroga J. Evaluating the services of torture rehabilitation programmes: history and recommendations. Torture. 2011 Jan;21(2):98140.

5. Montgomery E, Patel N. Torture rehabilitation: reflections on treatment outcome studies. Torture. 2011 Jan;21(2):141-5.

6. Weiss WM, Ugueto AM, Mahmooth Z, Murray LK, Hall BJ, Nadison M, et al. Mental health interventions and priorities for research for adult survivors of torture and systematic violence: a review of the literature. Torture J. 2016;26(1):17-45.

7. Fabri MR, Best, promising and emerging practices in the treatment of trauma : Torture. 2011;21(1):27-38.

8. Palic S, Elklit A. An explorative outcome study of CBT-based multidisciplinary treatment in a diverse group of refugees from a Danish treatment centre for rehabilitation of traumatized refugees. Torture. 2009;19:248-70.

9. Buhmann C, Andersen I, Mortensen EL, Ryberg J, Nordentoft M, Ekstrøm M. Cognitive behavioral psychotherapeutic treatment at a psychiatric trauma clinic for Refugees: description and evaluation. Torture J. 2015;25(1):17-32.

10. Larson-Stoa D, Jacobs GA, Jonathan A, Poudyal B. Effect of counseling by paraprofessionals on depression, anxiety, somatization, and functioning in Indonesian torture survivors. Torture. 2015;25(2):1-11.

11. Manneschmidt S, Griese K, Shamloo S, Zimmerman C, Walker MD, Hernandez AM, et al. Evaluating psychosocial group counselling with afghan women: is this a useful intervention? Torture. 2009; 19:41-50.

12. Buhmann C, Mortensen EL, Nordentoft M, Ryberg J, Ekstrøm M. Follow-up study of the treatment outcomes at a psychiatric trauma clinic for refugees. Torture J. 2015;25(1):1-16.

13. Kira IA, Ahmed A, Mahmoud V, Wasim F. Group therapy model for refugee and torture survivors. Torture. 2010;20:108-13.
14. Kinzie JD, Kinzie JM, Sedighi B, Woticha A, Mohamed H, Riley C. Prospective one-year treatment outcomes of tortured refugees: a psychiatric approach. Torture Q J Rehabil Torture Vict Prev Torture. 2012;22(1):1-10.

15. Hárdi L, Kroo A. Psychotherapy and psychosocial care of torture survivor refugees in Hungary. Torture. 2011;21(2):84-97.

16. Vindbjerg E, Klimpke C, Carlsson J. Psychotherapy with traumatised refugees - the design of a randomised clinical trial. Torture. 2014;24(Trial 1):40-8.

17. Curling P. The effectiveness of empowerment workshops with torture survivors. Torture. 2005;15(1):9-15.

18. McKinney MM. Treatment of survivors of torture: spiritual domain. Torture. 2011;21(1):61-6.

19. Somnier FE, Genefke IK. Psychotherapy for victims of torture. The British journal of psychiatry : the journal of mental science. 1986. p. 323-9.

20. Longacre M, Silver-Highfield E, Lama P, Grodin $\mathrm{M}$. Complementary and alternative medicine in the treatment of refugees and survivors of torture: a review and proposal for action. Torture. 2012;22:38-57.

21. Salo CD, Bray EM. Empirically tested interventions for torture survivors: A systematic review through an ecological lens. Transl Issues Psychol Sci. 2016;2(4):449-63.

22. Allodi F. Assessment and treatment of torture victims: a critical review. J Nerv Ment Dis. 1991;179:4-11.

23. Slobodin O, de Jong JTVM. Family interventions in traumatized immigrants and refugees: A systematic review. Transcult Psychiatry. 2015 Dec;52(6):723-42.

24. Kaplan I, McFarlane CA. Evidence-based psychological interventions for adult survivors of torture and trauma: A 30-year review. Transcultural Psychiatry. 2012. p. 539-67.

25. Joshua M. Review of A mental healthcare model for mass trauma survivors: Control-focused behavioral treatment of earthquake, war and torture trauma. Psychiatr Serv. 2013;64:e3.

26. Crosby SS. Primary care management of nonenglish-speaking refugees who have experienced trauma: A clinical review. JAMA. 2013;310:51928.

27. Regel S, Berliner P. Current perspectives on assessment and therapy with survivors of torture: the use of a cognitive behavioural approach. Eur J Psychother Couns. 2007 Sep;9(3):289-99.

28. Thurston WE, Ramaliu A. Evaluability assessment of a survivors of torture program: Lessons learned. Can J Progr Eval. 2005;20:1-25. 
29. Amris S, Arenas JG. Impact Assessment in Rehabilitation - a long-term research strategy based on a global multi-centre study design . 1 . Introduction The issues around the quality of health care and provision of health care services have become a subject of increasing compl. Psyke \& Logos. 2004;25:13-36.

30. Carlsson JM, Olsen DR, Kastrup M, Mortensen EL. Late Mental Health Changes in Tortured Refugees in Multidisciplinary Treatment. J Nerv Ment Dis. 2010 Nov;198(11):824-8.

31. McColl H, Higson-Smith C, Gjerding S, Omar MH, Rahman B, Hamed M, et al. Rehabilitation of torture survivors in five countries: common themes and challenges. Int J Ment Health Syst. 2010;4(1):16

32. Campbell TA, Clay R, Vrana SR. Survey of National Consortium of Torture Treatment Program Therapists About the Assessment, Diagnosis, and Treatment of the Psychological Sequelae of Torture. Traumatology. 2012.

33. Buhmann CB, Nordentoft $M$, Ekstroem $M$, Carlsson J, Mortensen EL. The effect of flexible cognitive-behavioural therapy and medical treatment, including antidepressants on posttraumatic stress disorder and depression in traumatised refugees: pragmatic randomised controlled clinical trial. Br J Psychiatry. 2016 Mar 1;208(3):252-9.

34. Başoğlu M. Rehabilitation of traumatised refugees and survivors of torture. BMJ Br Med J. 2006;333(7581):1230-1.

35. Jaranson JM. Rehabilitation of traumatised refugees and survivors of torture: a reply to Basoglu. BMJ. 2006 Dec 16;333(7581):1230-1.

36. Wampold BE, Flückiger C, Del Re AC, Yulish NE, Frost ND, Pace BT, et al. In pursuit of truth: A critical examination of meta-analyses of cognitive behavior therapy. Psychother Res. 2017 Jan 2;27(1):14-32.

37. Wampold BE, Mondin GW, Moody M, Stich F, Benson K, Ahn H. A Meta-Analysis of Outcome Studies Comparing Bona Fide Psychotherapies: Empirically, "All Must Have Prizes" Bruce. Psychol Bull. 1997;122(3):203-15.

38. Lambert, M. J., \& Bergin AE. The effectiveness of psycho- therapy. In: Garfield AEB\& SL, editor. Handbook of psycho- therapy and behavior change. Hand: New York: Wiley.; 1994. p. 143-89.

39. Lambert MJ. Bergin \& Garfield's handbook of psychotherapy and behavior change (6th ed). New York: Wiley; 2013.

40. Lambert MJ, Ogles BM. Common factors: Post hoc explanation or empirically based therapy approach? Psychotherapy. 2014;51(4):500-4.
40. Fiedler FE. Factor analyses of psychoanalytic, non-directive, and Adlerian therapeutic relationships. J Consult Psychol. 1951;15(1):32-8.

41. Rosenzweig $S$. Some implicit common factors in diverse methods of psychotherapy. Am J Orthopsychiatry. 1936;6(3):412-5.

42. Frank JD. Persuasion and Healing. Baltimore: John Hopkins University Press; 1961.

43. Grencavage LM, Norcross JC. Where are the commonalities among the therapeutic common factors? Prof Psychol Res Pract. 1990;21(5):372-8.

44. Stein D, Zungu-Dirwayi N, van der Linden G, Seedat S. Pharmacotherapy for post traumatic stress disorder (PTSD). In: Stein D, editor. Cochrane Database of Systematic Reviews. Chichester, UK: John Wiley \& Sons, Ltd; 2000.

45. Hoskins M, Pearce J, Bethell A, Dankova L, Barbui C, Tol WA, et al. Pharmacotherapy for post-traumatic stress disorder: systematic review and meta-analysis. Br J Psychiatry. 2015 Feb 1;206(2):93-100.

46 Laska KM, Gurman AS, Wampold BE. Expanding the lens of evidence-based practice in psychotherapy: A common factors perspective. Psychotherapy. 2014;51(4):467-81.

47. Torture CV of. Restoring Hope and Dignity : Manual for Group Counseling Center for Victims of Torture. Minnesota; 2016.

48. Laveta V, Orieny P. Efficacy of rehabilitation and treatment approaches: Group counseling torture treatment model for low-resource settings. In: IRCT 10th International Scientific Symposium Delivering on the promise of the right to rehabilitation Mexico City, 5-7 December 2016. 2016.

49. Bertoni M, Gierlach E, Kimpara S, Beutler L. Empirically Supported Treatments and Comparative Psychotherapy Outcome Research. In: Richard DCS, Huprich SK, editors. Clinical Psychology: Assessment, Treatment, and Research. 2009. p. 399-422.

50. Beutler L, Harwood M, Bertoni M, Thoman J. Systematic Treatment Selection and Prescriptive Therapy. In: Stricker G, Gold J, editors. Casebook of Psychotherapy Integration. 2006. p. 29-42.

51. Cunningham M, Cunningham JD. Patterns of symptomatology and patterns of torture and trauma experiences in resettled refugees. Aust $N$ Z J Psychiatry. 1997;31:555-65.

52. Loneragan C, Steel Z, Touze D le, Harris E, Ceollo M, Susljik I, et al. Torture, Mental Health Status and the Outcomes of Refugee Applications among Recently Arrived Asylum Seekers in Australia. International Journal of Migration, Health and Social Care. 2006. p. 4-14. 
53. Murray LK, Dorsey S, Haroz E, Lee C, Alsiary MM, Haydary A, et al. A Common Elements Treatment Approach for Adult Mental Health Problems in Low- and Middle-Income Countries. Cogn Behav Pract. 2014 May;21(2):111-23.

54. Hinton DE, Rivera EI, Hofmann SG, Barlow DH, Otto MW. Adapting CBT for traumatized refugees and ethnic minority patients: Examples from culturally adapted CBT (CA-CBT). Transcult Psychiatry. 2012 Apr;49(2):340-65.

55. Potocky M, Guskovict KL. Enhancing empathy among humanitarian workers through Project MIRACLE: Development and initial validation of the Helpful Responses to Refugees Questionnaire. Torture. 2016;26(3):46-60.

56. Silove D. The psychosocial effects of torture, mass human rights violations, and refugee trauma: toward an integrated conceptual framework. J Nerv Ment Dis. 1999;187:200-7.

57. Tay AK, Silove D. The ADAPT model: bridging the gap between psychosocial and individual responses to mass violence and refugee trauma. Epidemiol Psychiatr Sci. 2017 Apr 15;26(2):142-5.

58. Silove D. The ADAPT model: a conceptual framework for mental health and psychosocial programming in post conflict settings. Intervention. 2013;11(3):237-48.

59. Tay AK, Rees S, Chen J, Kareth M, Mohsin M, Silove D. The Refugee-Mental Health Assessment Package (R-MHAP); rationale, development and first-stage testing amongst West Papuan refugees. Int J Ment Health Syst. 2015 Dec 10;9(1):29

60. O'Mara S, O'Mara S. Torturing the brain: on the folk psychology and folk neurobiology motivating "enhanced and coercive interrogation techniques”. Trends Cogn Sci. 2009;13(12):497-500.

61. Catani C, Adenauer H, Keil J, Aichinger H, Neuner F. Pattern of cortical activation during processing of aversive stimuli in traumatized survivors of war and torture. Eur Arch Psychiatry Clin Neurosci. 2009 Sep;259(6):340-51.

62. Elbert T, Schauer M, Ruf M, Weierstall R, Neuner F, Rockstroh B, et al. The Tortured Brain. Z Psychol. 2011 Jan;219(3):167-74.

63. Pérez-Sales P. Psychological Torture: definition, evaluation and measurement. London-New York: Routledge; 2016.

64. Reeler T, Chitsike K, Maizva F, Reeler B. The Tree of Life: a community approach to empowering and healing the survivors of torture in Zimbabwe. Torture. 2009;19:180-93.

65. DeRubeis RJ, Lorenzo-Luaces L. Recognizing that truth is unattainable and attending to the most informative research evidence. Psychother Res. 2017 Jan 2;27(1):33-5.
66. Staub E, Pearlman LA, Gubin A, Hagengimana A. Healing, Reconciliation, Forgiving and the Prevention of Violence after Genocide or Mass Killing: An Intervention and Its Experimental Evaluation in Rwanda. J Soc Clin Psychol. 2005;24(3):297-334.

67. Morris P, Silove D. Cultural influences in psychotherapy with refugee survivors of torture and trauma. Hosp Community Psychiatry. 1992;43:820-4. 